Research Article

\title{
Research on Control Strategy of the Electric Power Steering System for All-Terrain Vehicles Based on Model Predictive Current Control
}

\author{
Chen Jie $\mathbb{D}^{1,2}$ and Guo Yanling $\mathbb{D}^{1}$ \\ ${ }^{1}$ College of Mechanical and Electrical Engineering, Northeast Forestry University, Harbin 150040, China \\ ${ }^{2}$ Gangyang Steering System Co., Ltd., Taizhou 225300, China
}

Correspondence should be addressed to Guo Yanling; guoyanling_nefu@163.com

Received 26 November 2020; Revised 13 December 2020; Accepted 2 March 2021; Published 15 March 2021

Academic Editor: Xiaodong Sun

Copyright (C) 2021 Chen Jie and Guo Yanling. This is an open access article distributed under the Creative Commons Attribution License, which permits unrestricted use, distribution, and reproduction in any medium, provided the original work is properly cited.

\begin{abstract}
Aiming at the high demand for the torque response speed and torque pulsation of the all-terrain vehicle (ATV) Electric Power Steering (EPS) system, this paper proposes to apply the Model Predictive Current Control to the all-terrain vehicle EPS system. A Novel Three-Vector Model Predictive Current Control (N3V-MPCC) is proposed in this paper to reduce the current ripple and reduce the calculation load. Two effective voltage vectors and a zero vector are selected in the control period through only six times of prediction and application of the Sector Vector Selection method. The duration of each voltage is calculated and output to the Voltage Source Inverter (VSI). Simulation and experimental results show that, compared with PID cascade Field Oriented Control (PI-FOC), N3C-MPCC can effectively reduce the ripple current of the $d$-axis and the $q$-axis. In the simulated electric power mode, the $q$-axis current ripple of the N3V-MPCC is reduced by $66.67 \%$. Experimental results show that the current ripple of the motor is reduced by $60 \%$, and the torque pulsation is reduced by $62.5 \%$. Therefore, N3V-MPCC has a faster current response speed and smooth steering torque.
\end{abstract}

\section{Introduction}

All-Terrain Vehicles (ATV) [1] are widely used in agriculture, forestry, entertainment, and military fields because of their excellent passing performance. The ATV uses lowpressure wide tires, making it easy to shuttle through harsh terrains such as sand and riverbeds. However, due to the large contact area between the tire and the ground, the unique tread pattern, the deep crown, and the handlebar steering structural characteristics, the steering resistance is considerable. The operation difficulty is increased. Therefore, the Electric Power Steering system (EPS) has become a necessary device for ATV [2]. EPS system has the advantages of lightweight, high efficiency, and energy-saving and gradually replaces the Hydraulic Power Steering system (HPS). EPS power-assisted motors mainly include Direct Current (DC) brushed motors and Surface Permanent
Magnet Synchronous Motors (SPMSM) [3]. The brushed DC motor has a short service life due to the structural factor. SPMSM has the characteristics of small size, high power density, and a large torque-to-inertia ratio $[4,5]$ and is widely used in electric vehicles [6] and industrial equipment fields. The motor control method is the key to the EPS system to achieve high steering accuracy and improve vehicle steering stability [7]. SPMSM can provide smoother electric power torque [8], which is beneficial to improve the driver's driving comfort, and gradually replace the brushed DC motors in the EPS system.

The current loop control strategy is a key factor in the design of the vehicle steering feel. The main control methods include PID current control $[9,10]$, Sliding Mode current control [11], Hysteresis control [12], and Model Predictive Control (MPC). The advantages of PID current control are simple and efficient. This method has two disadvantages: one 
is that PID control contains the integral link, which has a certain hysteresis; the second is that PID does not contain the information of the controlled object, so a lot of experiments are needed to set proper PID parameters. Sliding Mode control has the characteristics of fast response and strong robustness [13]. However, in the real system, due to time lag, system delay, and measurement error, the sliding mode movement is accompanied by high-frequency jitter, which affects the dynamic performance of the steering system. Hysteresis Control, also known as bang-bang control, has strong robustness. Due to the lack of model information and the steps to find the optimal solution, hysteresis control leads to unstable switching frequency, high losses, and high ripple current. Model Predictive Control (MPC) originated in the 1960s. The algorithm discretizes the mathematical model of the system, uses the cost function to evaluate the influence of the control variable on the error between the predicted value and the reference value [14], and calculates the optimal control variable of the system through the rolling optimization method. MPC has the characteristics of fast dynamic response, simple and flexible control [15]. In recent years, with the development of integrated circuit design and manufacturing technology and the improvement of the computing power of integrated chips such as Digital Signal Processor (DSP), the application of MPC in the field of power electronics has become a research hotspot [16].

The current EPS system research is based on accurate mathematical models, and it has become a trend to use MPC to design control strategies. In the field of motor control, MPC can be divided into Continuous-Control-Set MPC (CCS-MPC) [17, 18] and Finite-Control-Set MPC (FCSMPC) [19]. Among them, CCS-MPC obtains the required voltage vector by solving the optimization problem online and uses the PWM module to obtain continuous output variables [20]. FCS-MPC uses the Voltage Source Inverter (VSI) discretization characteristics to enumerate all switch combinations and then select the optimal voltage vector by calculating the minimum value of the cost function. Compared with the CCS-MPC algorithm, the FCS-MPC algorithm is more concise and has less computational load. According to the different types of optimization targets, FSC-MPC includes Model Predictive Torque Control (MPTC) [21-23] and Model Predictive Current Control (MPCC) $[24,25]$. The MPTC method needs to design the weight factor, which increases the difficulty of solving the optimization problem. MPCC uses the motor $d$-axis and $q$ axis currents as control variables and does not need to design weight factor, nor does it need to predict torque and flux linkage, which is simpler than the MPTC algorithm. According to the number of vector outputs in a single control cycle of MPCC, it can be divided into single-vector MPCC [21, 26], two-vector MPCC [27-30], and three-vector MPCC $[31,32]$. The direction and amplitude of the voltage vector are fixed in the single-vector MPCC. There is overshoot or undershoot current tracking, resulting in large current ripples and poor system performance. The twovector MPCC can output two voltage vectors in a single sampling period. Although this control method improves the system performance, it is difficult to ensure that the control performance is optimal because the second voltage vector is the constant zero vector. Many scholars have made improvements on this basis. The study in [28] proposed using the estimated back Electromotive Force (EMF) to predict the stator current. Despite reducing the current pulsation and improving the system stability, the estimated back EMF value increases the control error. The study in [30] proposes a method of selecting the combination of two voltage vectors and calculates the two voltage vectors duration simultaneously by optimizing the value function to obtaining better dynamic and static performance. However, the total number of combinations required for this method is $7+6+\cdots+1=28$. The optimal voltage vector is selected in 28 prediction sets, resulting in a large calculation load. The three-vector MPCC outputs two effective voltages and a zero vector in a single control period. The study in [32] proposed a method of combining the active vectors with duty cycle and virtual vectors with duty cycle. However, the large number of candidate vectors is not conducive to real-time optimization, has a large calculations load, and requires high hardware. Therefore, this paper proposes a Novel ThreeVector Model Predictive Current Control (N3V-MPCC), which obtains the first optimal vector through 6 iterations. Combine the deadbeat current principle and the SPMSM mathematical model; calculate the error between the target vector and the first optimal vector. According to the vector error, use the Sector Vector Selection method to select the second optimal vector. Finally, adjust the amplitude and direction of the output vector by the zero vector, reducing the ripple current and reducing the calculation load. This method is applied to the EPS system of ATV. Compared with the traditional PID Cascade Field Oriented Control (PIFOC) strategy, it is verified that the N3V-MPCC has a faster dynamic response speed and better steering feel.

The structure of this paper is as follows: The second section establishes the dynamic model of the EPS system of ATV. The third section introduces the principle of N3VMPCC. The fourth section carries out the simulation analysis based on the established model and carries out vehicle experiment verification. Finally, the conclusion is given in Section 5.

\section{Model of EPS Systems}

The ATV adopts a rocker-type steering mechanism, which mainly includes a handlebar steering wheel, a steering column, an EPS component, a steering rocker arm, and a steering rod. The structure is shown in Figure 1. The EPS components include a torque sensor, a deceleration mechanism, an SPMSM, and an Electronic Control Unit (ECU). When the vehicle starts or is driven, the torque sensor on the steering column detects the driver's torque on the steering wheel and transmits the torque signal to the ECU. Then, the ECU controls the SPMSM to provide electric torque. Ensure the portability of the driver's steering process.

The dynamic model of the EPS system is determined by the interrelationship between the following three aspects: the 


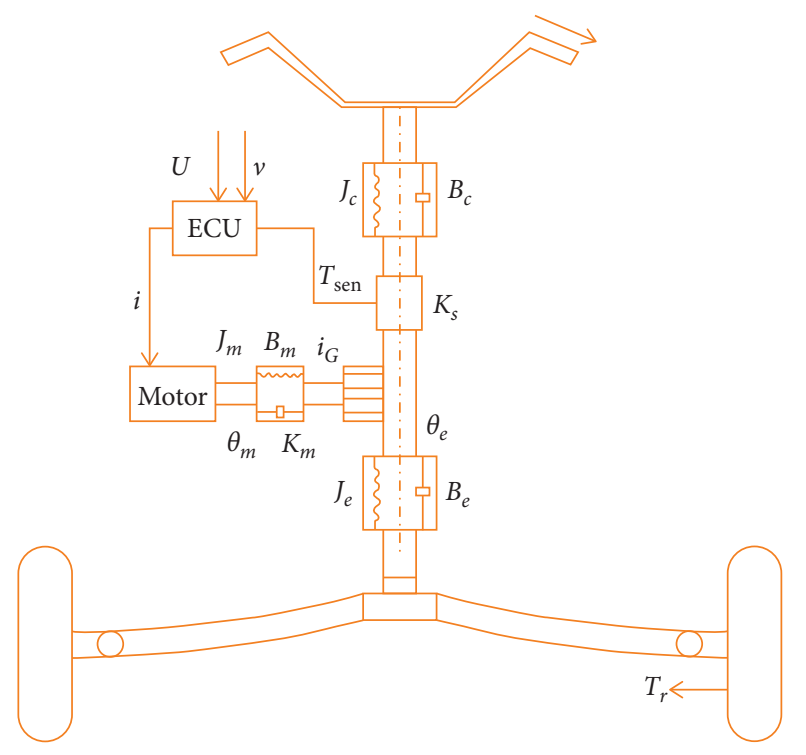

FIgURE 1: EPS system structure of ATV.

steering mechanism, the dynamic characteristics of the motor, and the reaction force of the ground on the tire. According to Newton's second law, combined with the structure shown in Figure 1, the nonlinear dynamic model of EPS is derived. The mathematical models between the steering wheel, steering column, and steering rocker are established, respectively, as follows:

$$
\begin{aligned}
J_{c} \ddot{\theta}_{c}+B_{c} \dot{\theta}_{c}+T_{\text {sen }} & =T_{d}, \\
T_{\text {sen }} & =K_{\text {sen }}\left(\theta_{c}-\theta_{e}\right), \\
\ddot{\theta}_{e}+B_{e} \dot{\theta}_{e}+T_{r} & =T_{\text {sen }}+T_{a}, \\
T_{a} & =K_{T} G\left(\theta_{m}-\theta_{e} G\right), \\
J_{m} \ddot{\theta}_{m}+B_{m} \dot{\theta}_{m}+K_{m}\left(\theta_{m}-\theta_{e} G\right) & =T_{m},
\end{aligned}
$$

where $\theta_{c}$ is the rotation angle of the steering wheel; $\theta_{e}$ is the rotation angle of the lower steering column; $T_{d}$ is the torque of the driver; $T_{\text {sen }}$ is the torsion bar torque; $K_{\text {sen }}$ is the stiffness coefficient of the torsion bar; $J_{e}$ is the moment of inertia of the steering column; $B_{e}$ is steering column steering damping; $T_{r}$ is the steering resistance torque; $T_{a}$ is the motor boost torque; $\theta_{m}$ is the motor rotation angle; $K_{T}$ is the motor torque coefficient; $G$ is the transmission ratio of the motor reduction mechanism; $J_{m}$ is the moment of inertia of the motor; $B_{m}$ is motor damping; and $T_{m}$ is electromagnetic torque.

The reaction torque $T_{r}$ of the steering column in the above equation is mainly composed of the friction between the tire and the ground and the friction torque of the mechanical rotation pair. The steering resistance torque is greatest during static steering. This article assumes that the steering system is well lubricated, and the friction loss torque is small, which is negligible. The maximum steering resistance torque $T_{r \max }$ is

$$
T_{r}=\frac{f}{3} \sqrt{\frac{F_{z}^{3}}{P}}
$$

where $f$ is the friction coefficient between the ground and the tire; $F_{z}$ is the front axle load of the vehicle; and $P$ is the tire pressure.

Synthesize the above equation to establish the state-space 0equation of the system to provide theoretical support for subsequent simulations. The state-space variable is $x=\left[\begin{array}{llllll}\theta_{c} & \dot{\theta}_{c} & \theta_{e} & \dot{\theta}_{e} & \theta_{m} & \dot{\theta}_{m}\end{array}\right]^{T}$. System input state-space variables areu $=\left[\begin{array}{lll}T_{d} & T_{m} & T_{r}\end{array}\right]^{T}$. The output state-space variable is $y=\left[\begin{array}{lllll}T_{a} & T_{\text {sen }} & \theta_{c} & \theta_{e} & \dot{\theta}_{m}\end{array}\right]^{T}$. The state-space equation of the system is

$$
\begin{aligned}
& \dot{x}=A x+B u, \\
& y=C x+D u,
\end{aligned}
$$

where

$$
A=\left[\begin{array}{cccccc}
0 & 1 & 0 & 0 & 0 & 0 \\
-\frac{K_{\mathrm{sen}}}{J_{c}} & -\frac{B_{c}}{J_{c}} & \frac{K_{\mathrm{sen}}}{J_{c}} & 0 & 0 & 0 \\
0 & 0 & 0 & 1 & 0 & 0 \\
\frac{K_{\mathrm{sen}}}{J_{e}} & 0 & -\frac{K_{\mathrm{sen}}+K_{T} \cdot G^{2}}{J_{e}} & -\frac{B_{e}}{J_{e}} \frac{K_{T} \cdot G}{J_{e}} & 0 \\
0 & 0 & 0 & 0 & 0 & 1 \\
0 & 0 & \frac{K_{T} G}{J_{m}} & 0 & -\frac{K_{T}}{J_{m}} & -\frac{B_{m}}{J_{m}}
\end{array}\right]
$$$$
B=\left[\begin{array}{ccc}
0 & 0 & 0 \\
-\frac{1}{J_{e}} & 0 & 0 \\
0 & 0 & 0 \\
0 & 0 & -\frac{1}{J_{e}} \\
0 & 0 & 0 \\
0 & \frac{1}{J_{m}} & 0
\end{array}\right] ;
$$$$
C=\left[\begin{array}{cccccc}
0 & 0 & -K_{T} G^{2} & 0 & K_{T} G & 0 \\
K_{\text {sen }} & 0 & -K_{\text {sen }} & 0 & 0 & 0 \\
1 & 0 & 0 & 0 & 0 & 0 \\
0 & 0 & 1 & 0 & 0 & 0 \\
0 & 0 & 0 & 0 & 0 & 0
\end{array}\right] ;
$$$$
D=\left[\begin{array}{lll}
0 & 0 & 0 \\
0 & 0 & 0 \\
0 & 0 & 0 \\
0 & 0 & 0 \\
0 & 0 & 0 \\
0 & 0 & 0
\end{array}\right] \text {. }
$$ 


\section{Principle of N3V-MPCC}

3.1. SPMSM Prediction Model. The N3V-MPCC method of SPMSM is based on the mathematical model of the system. Using current as the variable, a prediction model based on the discrete state-space equations of the system is established, and a rolling optimization method is used to realize the current control of SPMSM. Without considering the parameter uncertainty, the electromagnetic model of the permanent magnet synchronous motor in the $d$-axis and $q$ axis coordinate system is

$$
\begin{aligned}
& L_{d} \frac{\mathrm{d} i_{d}}{\mathrm{~d} t}=-R_{s} i_{d}+\omega_{e} L_{q} i_{q}+u_{d}, \\
& L_{q} \frac{\mathrm{d} i_{q}}{\mathrm{~d} t}=-R_{s} i_{q}-\omega_{e} L_{d} i_{d}-\omega_{e} \psi_{f}+u_{q},
\end{aligned}
$$

where $u_{d}$ is the $d$-axis stator voltage; $u_{q}$ is the $q$-axis stator voltage; $i_{d}$ is the $d$-axis stator current; $i_{q}$ is the $d$-axis stator current; $L_{d}$ is the $d$-axis stator inductance; $L_{q}$ is the $q$-axis stator inductance; $\omega_{e}$ is the electrical angular velocity of the rotor; $\psi_{f}$ is the permanent magnet flux; and $R_{s}$ is the stator resistance.

According to equations (5) and (6), the continuous statespace equation of SPMSM is derived [33]:

$\left[\begin{array}{c}\frac{\mathrm{d} i_{d}}{\mathrm{~d} t} \\ \frac{\mathrm{d} i_{q}}{\mathrm{~d} t}\end{array}\right]=\left[\begin{array}{cc}-\frac{R_{s}}{L_{d}} & \frac{\omega_{e} L_{q}}{L_{d}} \\ -\frac{\omega_{e} L_{d}}{L_{q}} & -\frac{R_{s}}{L_{q}}\end{array}\right]\left[\begin{array}{l}i_{d} \\ i_{q}\end{array}\right]+\left[\begin{array}{cc}\frac{1}{L_{d}} & 0 \\ 0 & \frac{1}{L_{q}}\end{array}\right]\left[\begin{array}{l}u_{d} \\ u_{q}\end{array}\right]+\left[\begin{array}{c}0 \\ -\frac{\omega_{e} \psi_{f}}{L_{q}}\end{array}\right]$

EPS system uses DSP as an arithmetic chip, so it is necessary to discretize continuous equations. Forward Euler discretization method is the simplest and most commonly used method. The continuous state-space equation (7) is discretized by the Forward Euler discretization method. The discrete SPMSM state-space equation is shown in the following equation:

$$
\left[\begin{array}{c}
i_{d}(k+1) \\
i_{q}(k+1)
\end{array}\right]=\left[\begin{array}{cc}
1-\frac{T_{s} R_{s}}{L_{d}} & \frac{T_{s} \omega_{e} L_{q}}{L_{d}} \\
-\frac{T_{s} \omega_{e} L_{d}}{L_{q}} & 1-\frac{T_{s} R_{s}}{L_{q}}
\end{array}\right]\left[\begin{array}{l}
i_{d}(k) \\
i_{q}(k)
\end{array}\right]+\left[\begin{array}{c}
\frac{T_{s}}{L_{d}} \\
0 \\
0 \\
\frac{T_{s}}{L_{q}}
\end{array}\right]\left[\begin{array}{l}
u_{d}(k) \\
u_{q}(k)
\end{array}\right]+\left[\begin{array}{c}
0 \\
T_{s} \omega_{e} \psi_{f} \\
L_{q}
\end{array}\right],
$$

where $T_{s}$ is the control period, which represents the value of the state variable of the $k$ th control period $(k=1,2,3, \ldots)$, and $i_{d}$ represents the predicted value of the $d$-axis current at the next sampling; $i_{d}(k+1)$ represents the predicted value of the $d$-axis current at the next sampling moment.

In a control period $T_{s}$, assuming that $R_{s}, L_{d}, L_{q}$, and $\psi_{f}$ are all known and constant quantities, since the speed $\omega_{e}$ changes slowly relative to the current and the control period $T_{s}$ is short, it is considered that the speed remains unchanged in a control period. Then the $d$-axis and $q$-axis stator currents at the $k$ th sampling time can be used to predict the future $d$-axis and $q$-axis stator currents at $k+1$ time. The prediction model of SPMSM is

$$
\left[\begin{array}{c}
i_{d}^{p}(k+1) \\
i_{q}^{p}(k+1)
\end{array}\right]=\left[\begin{array}{cc}
1-\frac{T_{s} R_{s}}{L_{d}} & \frac{T_{s} \omega_{e} L_{q}}{L_{d}} \\
-\frac{T_{s} \omega_{e} L_{d}}{L_{q}} & 1-\frac{T_{s} R_{s}}{L_{q}}
\end{array}\right]\left[\begin{array}{l}
i_{d}(k) \\
i_{q}(k)
\end{array}\right]+\left[\begin{array}{cc}
\frac{T_{s}}{L_{d}} & 0 \\
0 & \frac{T_{s}}{L_{q}}
\end{array}\right]\left[\begin{array}{l}
u_{d}(k) \\
u_{q}(k)
\end{array}\right]+\left[\begin{array}{c}
0 \\
T_{s} \omega_{e} \psi_{f} \\
L_{q}
\end{array}\right],
$$

where $i_{d}^{p}(k+1)$ indicates the predicted value of the $d$-axis stator current and $i_{q}^{p}(k+1)$ indicates the predicted value of the $q$-axis stator current.

The SPMSM control system studied in this paper is based on a three-phase two-level VSI, and the structure is shown in Figure 2. Each bridge of the VSI has two switching states: on and off, represented by 1 and 0 , respectively. $S_{A}=1$ means that the upper half-bridge of phase $A$ is on and the lower half-bridge is off. $S_{A}=0$ means that the lower half-bridge of phase $A$ is on, and the upper half-bridge is off. The three-phase two-level VSI can output two zero vectors $\left(V_{0}\right.$ and $\left.V_{7}\right)$ and six effective voltage vectors, forming a limited control set $\mathrm{FCS}=\left\{v_{s}=V_{i}, i=0,1,2, \ldots, 7\right\}$.

According to the eight conduction combinations of the VSI, the voltage of each phase under eight states is calculated. According to Clarke's transformation, we use equation (10) to obtain the components and the stator voltage in the $\alpha$ - $\beta$-axis stationary coordinate system. Table 1 shows the switch states of FCS and the corresponding values of $u_{\alpha}$ and $u_{\beta}$. 


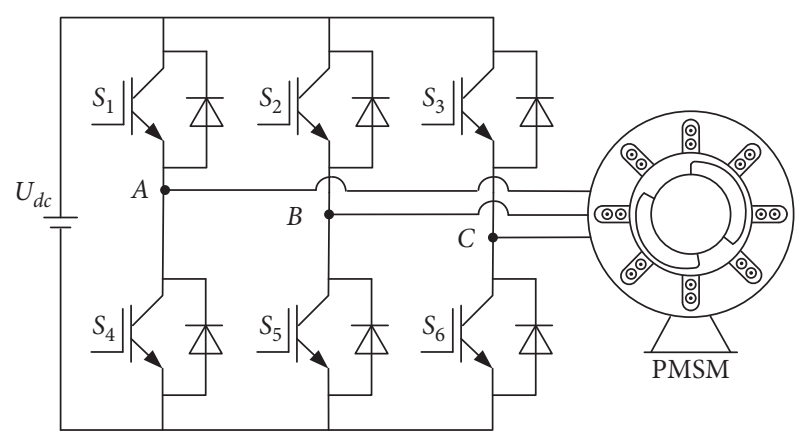

FIGURE 2: Structure of three-phase two-level VSI-driven SPMSM.

TABLE 1: Three-phase two-level VSI switching state.

\begin{tabular}{|c|c|c|c|}
\hline FCS & $S_{A} S_{B} S_{C}$ & $u_{\alpha}$ & $u_{\beta}$ \\
\hline$V_{0}$ & 0000 & 0 & 0 \\
\hline$V_{1}$ & $\begin{array}{lll}0 & 01\end{array}$ & $2 V_{d c} / 3$ & 0 \\
\hline$V_{2}$ & 011 & $V_{d c} / 3$ & $V_{d c} / \sqrt{3}$ \\
\hline$V_{3}^{2}$ & 010 & $-V_{d c} / 3$ & $V_{d c} / \sqrt{3}$ \\
\hline$V_{4}$ & 110 & $-2 V_{d c} / 3$ & 0 \\
\hline$V_{5}$ & 100 & $-V_{d c} / 3$ & $-V_{d c} / \sqrt{3}$ \\
\hline$V_{6}$ & 101 & $V_{d c} / 3$ & $-V_{d c} / \sqrt{3}$ \\
\hline$V_{7}$ & 111 & 0 & 0 \\
\hline
\end{tabular}

$$
\left[\begin{array}{l}
u_{\alpha} \\
u_{\beta}
\end{array}\right]=\frac{2 V_{d c}}{9}\left[\begin{array}{ccc}
1 & -\frac{1}{2} & -\frac{1}{2} \\
0 & \frac{\sqrt{3}}{2} & -\frac{\sqrt{3}}{2}
\end{array}\right]\left[\begin{array}{ccc}
2 & -1 & -1 \\
-1 & 2 & -2 \\
-1 & -1 & 2
\end{array}\right]\left[\begin{array}{l}
S_{A} \\
S_{B} \\
S_{C}
\end{array}\right]
$$

According to Table 1 , the values of $u_{\alpha}(k)$ and $u_{\beta}(k)$ of all switch combinations in one cycle can be obtained. After Park transformation, the values of $u_{d}(k)$ and $u_{q}(k)$ are obtained and put into the prediction model equation (9) for the current prediction. The predicted current values of eight switch combinations in the control period are calculated, and the optimal voltage vector is selected according to the minimum value of the cost function.

The cost function is an important part of the MPCC algorithm. The target of the cost function of the MPCC algorithm is to track the target current accurately. The cost function of MPCC designed in this paper is to calculate the voltage with the smallest error between the predicted current value and the target-current value as the optimal voltage vector. The cost function is shown in the following equation:

$$
\left\{\begin{array}{l}
g_{i}=\left|i_{q}^{*}-i_{q}(k+1)\right|+\left|i_{d}^{*}-i_{d}(k+1)\right|, \\
i \in\{0,1,2,3, \ldots, 7\}
\end{array}\right.
$$

where $i_{q}^{*}$ is the target value of the stator current $q$-axis component and $i_{d}^{*}$ is the $d$-axis component of the stator current target.

3.2. Vector Selection. The predicted current values of all combinations in the FCS set are imported into equation (11), and the switch combination that makes $g_{i}$ minimum is the optimal voltage vector. However, due to the limitation of the selectable voltage vector in the FCS, there is only one vector action per control period. The direction and amplitude of the voltage vector issued by the VSI are fixed. Compared with PI-FOC, single-vector MPC has lower control accuracy. Therefore, based on single-vector control, a two-vector MPCC is proposed. The FCS is traversed twice in a control cycle. In that case, two optimal voltage vectors can be selected, so the ripple current is reduced, and the control accuracy of the variables is improved. However, as the two voltage vectors of three-phase VSI can produce 64 possible combinations, the calculation amount of all combinations is too large to be applied in the EPS system. Therefore, it is necessary to simplify traversal steps, reduce the calculation load, improve the control precision, and reduce the ripple current [34].

First, according to the above method, the first optimal voltage vector $V_{\text {optl }}$ is selected from the effective voltage vector $\left(V_{1} \sim V_{6}\right)$. According to the combination in Table 1 , find the values of $u_{\alpha_{-} \text {opt1 }}$ and $u_{\beta_{-} \text {opt1 }}$ corresponding to $V_{\text {opt1 }}$, and get the values of $u_{d_{-} \text {opt1 }}$ and $u_{q_{-} \text {opt1 }}$ in the dynamic coordinate system by Park's transformation. According to the target current and current of the $d$-axis and $q$-axis in the control period, combined with the deadbeat control principle, the target voltage of the $d$-axis and $q$-axis is calculated by the following equation:

$$
\left[\begin{array}{c}
u_{d}^{*} \\
u_{q}^{*}
\end{array}\right]=\left[\begin{array}{cc}
\frac{L_{d}}{T_{s}} & 0 \\
0 & \frac{L_{q}}{T_{s}}
\end{array}\right]\left[\begin{array}{c}
i_{d}^{*} \\
i_{q}^{*}
\end{array}\right]+\left[\begin{array}{cc}
R_{s}-\frac{L_{d}}{T_{s}} & -\omega_{e} L_{q} \\
\omega_{e} L_{d} & R_{s}-\frac{L_{q}}{T_{s}}
\end{array}\right]\left[\begin{array}{l}
i_{d}(k) \\
i_{q}(k)
\end{array}\right]+\left[\begin{array}{c}
0 \\
\omega_{e} \psi_{f}
\end{array}\right],
$$

where $u_{d}^{*}(k)$ and $u_{q}^{*}(k)$ are the $d$-axis and $q$-axis target voltages, respectively.

Second, calculate the error $\Delta u_{d g}$ and $\Delta u_{q g}$ between the target voltage and the selected first optimal voltage, as shown in the following equations:

$$
\begin{aligned}
& \Delta u_{d g}=u_{d}^{*}-u_{d_{-} \mathrm{opt} 1}, \\
& \triangle u_{q g}=u_{q}^{*}-u_{q_{-} \mathrm{opt} 1} .
\end{aligned}
$$

Third, the voltage error obtained by the above equation is subjected to inverse Park's transformation to get the voltage errors $\Delta u_{g \alpha}$ and $\Delta u_{g \beta}$ in the $\alpha$ - $\beta$-coordinate system, and the error voltage vector $u_{s}^{*}$ is synthesized.

Fourth, a method of Sector Vector Selection is proposed. With six effective voltage vectors as the center, a sector is divided every $60^{\circ}$, and a total of 6 sectors are divided. As shown in Figure 3, the middle of the two sets of dashed lines is a sector. According to the sector where the error voltage vector $u_{s}^{*}$ is located, the effective voltage vector in the sector is selected as the second optimal voltage vector $V_{\text {opt2 }}$. Such as the error voltage vector $u_{s}^{*}$ in the IV sector, choose $V_{4}$ as the second optimal voltage vector $V_{\text {opt2 }}$. This method eliminates the second traversal of the entire FCS calculation process and reduces the computational complexity of the algorithm. 


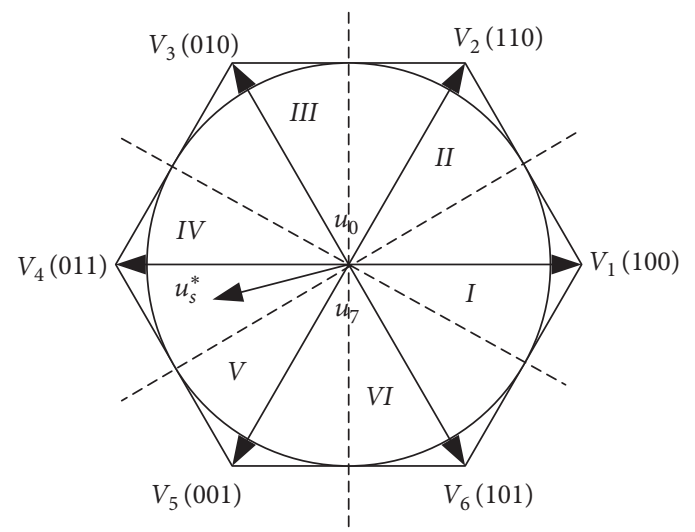

FIGURE 3: Division of voltage sector.

Fifth, in the N3V-MPCC algorithm, $V_{\text {opt1 }}, V_{\text {opt2 }}$ and the zero vector work together in one control cycle. To calculate the effective voltage vector and the zero vector duration, we need to know the rate of stator current change first. Define the $d$-axis and $q$-axis change rates of current $\delta_{d}$ and $\delta_{q}$, as shown in the following equations:

$$
\begin{aligned}
& \delta_{d}=\frac{\mathrm{d} i_{d}}{\mathrm{~d} t}=\frac{1}{L_{s}}\left(-R_{s} i_{a}+\omega_{e} L_{s} i_{q}+u_{d}\right), \\
& \delta_{q}=\frac{\mathrm{d} i_{q}}{\mathrm{~d} t}=\frac{1}{L_{s}}\left(-R_{s} i_{q}-\omega_{e} L_{s} i_{d}-\omega_{e} \psi_{f}+u_{q}\right) .
\end{aligned}
$$

The stator change rates of the current corresponding to the zero vector, the first optimal voltage vector, and the second optimal voltage vector are shown in the following equations:

$$
\begin{aligned}
& \delta_{d_{-} 0}=\left.\frac{\mathrm{d} i_{d}}{\mathrm{~d} t}\right|_{u_{d}=0}=\frac{1}{L_{s}}\left(-R_{s} i_{d}+\omega_{e} L_{s} i_{q}\right) \\
& \delta_{q_{-} 0}=\left.\frac{\mathrm{d} i_{q}}{\mathrm{~d} t}\right|_{u_{q}=0}=\frac{1}{L_{s}}\left(-R_{s} i_{q}-\omega_{e} L_{s} i_{d}-\omega_{e} \psi_{f}\right), \\
& \delta_{d_{-} \mathrm{opt} 1}=\left.\frac{\mathrm{d} i_{d}}{\mathrm{~d} t}\right|_{u_{d}=V_{d_{-} \mathrm{opt1}}}=\delta_{d_{-} 0}+\frac{V_{d_{-} \mathrm{opt} 1}}{L_{s}}, \\
& i_{d}(k+1)=i_{d}(k)+\delta_{d_{-} \mathrm{opt} 1} t_{\mathrm{opt} 1}+\delta_{d_{-} \mathrm{opt} 2} t_{\mathrm{opt} 2}+\delta_{d_{-} 0}\left(T_{s}-t_{\mathrm{opt} 1}-t_{\mathrm{opt} 2}\right)=i_{d}^{*}, \\
& i_{q}(k+1)=i_{q}(k)+\delta_{q_{-} \mathrm{opt} 1} t_{\mathrm{opt} 1}+\delta_{q_{-} \mathrm{opt} 2} t_{\mathrm{opt} 2}+\delta_{q_{-} 0}\left(T_{s}-t_{\mathrm{opt} 1}-t_{\mathrm{opt} 2}\right)=i_{q}^{*},
\end{aligned}
$$

where $t_{\text {opt } 1}$ is the duration of the first optimal voltage vector and $t_{\mathrm{opt} 2}$ is the duration of the second optimal voltage vector.

$$
\begin{aligned}
& \delta_{q_{-} \mathrm{opt} 1}=\left.\frac{\mathrm{d} i_{q}}{\mathrm{~d} t}\right|_{u_{q}=V_{q_{-} \mathrm{opt} 1}}=\delta_{q_{-} 0}+\frac{V_{q_{-} \mathrm{opt} 1}}{L_{s}}, \\
& \delta_{d_{-} \mathrm{opt} 2}=\left.\frac{\mathrm{d} i_{d}}{\mathrm{~d} t}\right|_{u_{d}=V_{d_{-} \mathrm{opt} 2}}=\delta_{d_{-} 0}+\frac{V_{q_{-} \mathrm{oppt} 2}}{L_{s}}, \\
& \delta_{q_{-} \mathrm{opt} 2}=\left.\frac{\mathrm{d} i_{q}}{\mathrm{~d} t}\right|_{u_{q_{1}}=V_{q_{-} \mathrm{opt} 2}}=\delta_{q_{-} 0}+\frac{V_{q_{-} \mathrm{opt} 2}}{L_{s}},
\end{aligned}
$$

where $\delta_{d_{-} 0}, \delta_{d_{-} \mathrm{opt} 1}$, and $\delta_{d_{-} \mathrm{opt} 2}$ are the zero vector, the first optimal voltage vector, and the second optimal voltage vector corresponding to the rate of change of the stator current on the $d$-axis; $\delta_{q_{-} 0}, \delta_{q_{-} \text {opt } 1}$, and $\delta_{q_{-} \text {opt2 }}$ are the zero vector, the first optimal voltage vector, and the second optimal voltage vector corresponding to the rate of change of the stator current on the $q$-axis; $V_{d_{-} \text {opt1 }}$ and $V_{d_{-} \text {opt1 }}$ are the voltage components of the $d$-axis and $q$-axis corresponding to $V_{\text {opt } 1}$; and $V_{d_{-} \text {opt2 }}$ and $V_{q_{-} \text {opt2 }}$ are the voltage components of the $d$-axis and $q$-axis corresponding to $V_{\text {opt2 }}$.

According to the stator change rate of current, the predicted current equation is changed into the following

$$
\begin{aligned}
t_{\mathrm{opt} 1} & =\left|\frac{1}{D}\left[\left(i_{d}^{*}-i_{d}(k)\right)\left(\delta_{q_{-} \mathrm{opt} 2}-\delta_{q_{-} 0}\right)+\left(i_{q}^{*}-i_{q}(k)\right)\left(\delta_{d_{-} 0}-\delta_{d_{-} \mathrm{opt} 2}\right)+T_{s}\left(\delta_{q_{-} 0} \delta_{d_{-} \mathrm{opt} 2}-\delta_{q_{-} \mathrm{opt} 2} \delta_{d_{-} 0}\right)\right]\right|, \\
t_{\mathrm{opt} 2} & =\left|\frac{1}{D}\left[\left(i_{d}^{*}-i_{d}(k)\right)\left(\delta_{q_{-} 0}-\delta_{q_{-} \mathrm{opt} 1}\right)+\left(i_{q}^{*}-i_{q}(k)\right)\left(\delta_{d_{-} \mathrm{opt} 1}-\delta_{d_{-} 0}\right)+T_{s}\left(\delta_{d_{-} 0} \delta_{q_{-} \mathrm{opt} 1}-\delta_{d_{-} \mathrm{opt} 1} \delta_{q_{-} 0}\right)\right]\right|, \\
t_{0} & =T_{s}-t_{\mathrm{opt} 1}-t_{\mathrm{opt} 2}
\end{aligned}
$$

According to equations (17)-(24), the duration of $t_{\mathrm{opt1}}$ and $t_{\text {opt2 }}$ is obtained, as shown in equations (25) and (26). 
where $\quad D=\delta_{q_{-} 0} \delta_{d_{-} \mathrm{opt} 2}+\delta_{q_{-} \mathrm{opt} 1} \quad \delta_{d_{-} 0}+\delta_{q_{-} \mathrm{opt} 2} \delta_{d_{-} \mathrm{opt} 1}$
$-\delta_{q_{-} \mathrm{opt} 1} \delta_{d_{-} \mathrm{opt} 2}-\delta_{q_{-} \mathrm{opt} 2} \delta_{d_{-} 0}-\delta_{q_{-} 0} \delta_{d_{-} \mathrm{opt} 1}$

When calculating the duration of the voltage vector, when $t_{\text {opt } 1}+t_{\text {opt2 }}$ is less than the control period $T_{s}$, the duration of the group of voltage vectors is output as $t_{\text {opt } 1}$, $t_{\text {opt2 }}$, and $t_{0}$. When $t_{\text {opt1 }}+t_{\text {opt2 }}$ is greater than the control period $T_{s}$, it is calculated and output, according to the following equation:

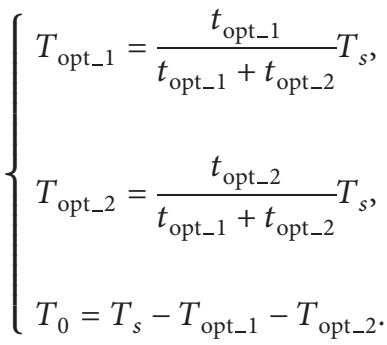

In summary, the SPMSM drive control block diagram of $\mathrm{N} 3 \mathrm{~V}-\mathrm{MPCC}$ proposed in this paper is shown in Figure 4.

\section{Simulation and Experiment}

MATLAB/Simulink is used to simulate and verify the proposed N3V-MPCC algorithm. The control scheme of the SPMSM system includes two-stage closed-loop control. The outer loop is PID speed control to eliminate the error between the reference speed and the actual speed, while the inner loop is current control. To compare the performance of the proposed N3V-MPCC with that of the traditional PIFOC, the outer loop of the two kinds of control uses PID to control the speed. The PI-FOC inner loop still uses PID to adjust the current error, and the N3V-MPCC is designed according to the structure of Figure 4. Parameters of SPMSM are shown in Table 2.

In the operating conditions of the EPS system, the motor speed will not exceed the rated speed. To obtain the maximum output torque and improve the operating efficiency of SPMSM, the control method with $i_{d}=0$ is often adopted. Under the same motor parameters, the PID parameters in the PI-FOC current loop are adjusted to the optimal value to simulate the current responses of N3V-MPCC and PI-FOC. When the load is $4.5 \mathrm{~N} \cdot \mathrm{m}$, the steering wheel rotates at a constant speed, and the $d$-axis current, $q$-axis current, and $A$-phase current of the two control strategies are compared. Figure 5(a) is the current curve of N3V-MPCC, and Figure 5(b) is the current curve of PI-FOC. It can be seen from Figure 5 that the $i_{d}$ value of N3V-MPCC current ripple amplitude within $\pm 0.38 \mathrm{~A}$, while the $i_{d}$ current ripple amplitude of PI-FOC is within $\pm 1 \mathrm{~A}$, and the $i_{d}$ deviation of N3C-MPCC is low. In SPMSM, through $A$-phase current comparison, the $A$-phase current ripple amplitude of $\mathrm{N} 3 \mathrm{~V}$ MPCC is lower, and the current curve is smoother.

Figure 6 shows the $i_{q}$ current values of N3V-MPCC and PI-FOC under a load of $4.5 \mathrm{~N} \cdot \mathrm{m}$. Both N3V-MPCC and PI-FOC are stable at $48 \mathrm{~A}$. However, PI-FOC has a more significant ripple current, with a maximum current ripple amplitude of $0.8 \mathrm{~A}$, while the maximum current ripple amplitude of N3V-MPCC is only $0.15 \mathrm{~A}$. Moreover, the time for PI-FOC to reach a steady state is slightly longer, which is $10 \mathrm{~ms}$ slower than N3V-MPC. Therefore, it shows that $\mathrm{N} 3 \mathrm{~V}-\mathrm{MPCC}$ has better dynamic response performance.

In the EPS system, the Microcontroller Unit (MCU) gives the corresponding target current $i_{q}$ through the assist curve table according to the vehicle speed and the steering wheel torque signal detected by the torque sensor. The simulation structure of the EPS system of the ATV is shown in Figure 7. To simplify the analysis, a spring device is used to simulate the actual steering resistance $T_{r}$. When the steering wheel rotates at a constant speed, the steering resistance increases, and the current required by the motor increases. Given the steering wheel angle and vehicle speed, the reference current $i_{q}$ is obtained through the assist parameter table. As the steering wheel turns, the steering resistance gradually increases, and the target value $i_{q}$ gradually increases. By comparing the $d$-axis and $q$-axis currents of N3V-MPCC and PI-FOC, the performance of the two control strategies is analyzed.

It can be seen from Figure 8 that the maximum current ripple amplitude of $i_{d}$ under the control of N3V-MPCC is $\pm 0.4 \mathrm{~A}$, which is small compared with the reference $i_{d}$ current. The $i_{d}$ current ripple amplitude of PI-FOC is high, with a maximum current ripple amplitude of $\pm 1.2 \mathrm{~A}$. It shows that the system stability of N3V-MPCC is better in the assist mode.

It can be seen from Figure 9 that both N3V-MPCC and PI-FOC increase with the increase of steering resistance, and the output current also gradually increases, realizing the function of electric power steering. When the required maximum torque is reached, the output current of N3VMOCC and PI-FOC can be stabilized at $48 \mathrm{~A}$. However, the $i_{q}$ current ripple amplitude of N3V-MPCC is $\pm 0.6 \mathrm{~A}$, and the $i_{q}$ current ripple amplitude of PI-FOC is $\pm 1.8 \mathrm{~A}$, indicating that the steering feel of the N3V-MPCC control strategy is better.

It can be seen from Figure 10 that under the two control strategies, the three-phase current of the SPMSM is sinusoidal. As the steering resistance increases, the amplitude of the three-phase current also increases. The three-phase ripple current of N3V-MPCC is low, and the three-phase ripple current of PI-FOC is high.

In summary, when the steering resistance gradually increases, the ripple currents of the $d$-axis, $q$-axis, and threephase of N3V-MPCC are lower than those of PI-FOC, which verifies that the N3V-MPCC has higher control accuracy and more stable output. To demonstrate the actual effect of the proposed N3V-MPCC, use DSP28335 as the main control chip to design the EPS controller and conduct realvehicle testing, as shown in Figure 11. The rotor position feedback element of the SPMSM is a rotary transformer to reduce the position calibration error of the motor. The control step of this system is one millisecond, and the Pulse Width Modulation (PWM) drive frequency is $10 \mathrm{kHz}$. This experiment uses dual resistors for current sampling. The current sampling period is 50 us. Sample the current values of $A$-phase and $B$-phase each time. 


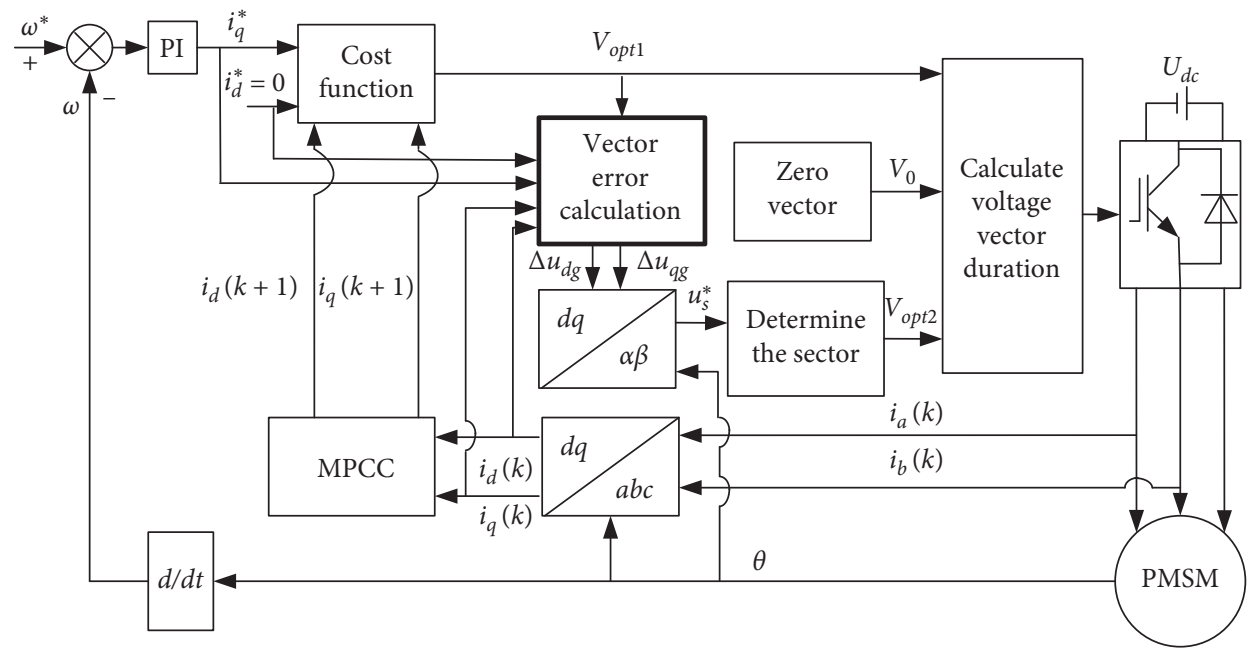

Figure 4: The control diagram of the N3V-MPCC.

TABle 2: Parameters of SPMSM.

\begin{tabular}{lc}
\hline Parameters & Value \\
\hline Stator resistance & $0.035 \Omega$ \\
Stator inductance & $0.000375 \mathrm{H}$ \\
Pole pairs & 3 \\
Magnet flux & $0.0245 \mathrm{~Wb}$ \\
Nominal power & $360 \mathrm{~W}$ \\
Nominal voltage & $12 \mathrm{~V}$ \\
Nominal current & $60 \mathrm{~A}$ \\
Nominal speed & $1560 \mathrm{r} / \mathrm{min}$ \\
Motor moment of inertia & $0.00019 \mathrm{~kg} / \mathrm{m}^{2}$ \\
Coefficient of friction & $0.0001 \mathrm{~N} \cdot \mathrm{m} \cdot \mathrm{s} / \mathrm{rad}$ \\
\hline
\end{tabular}
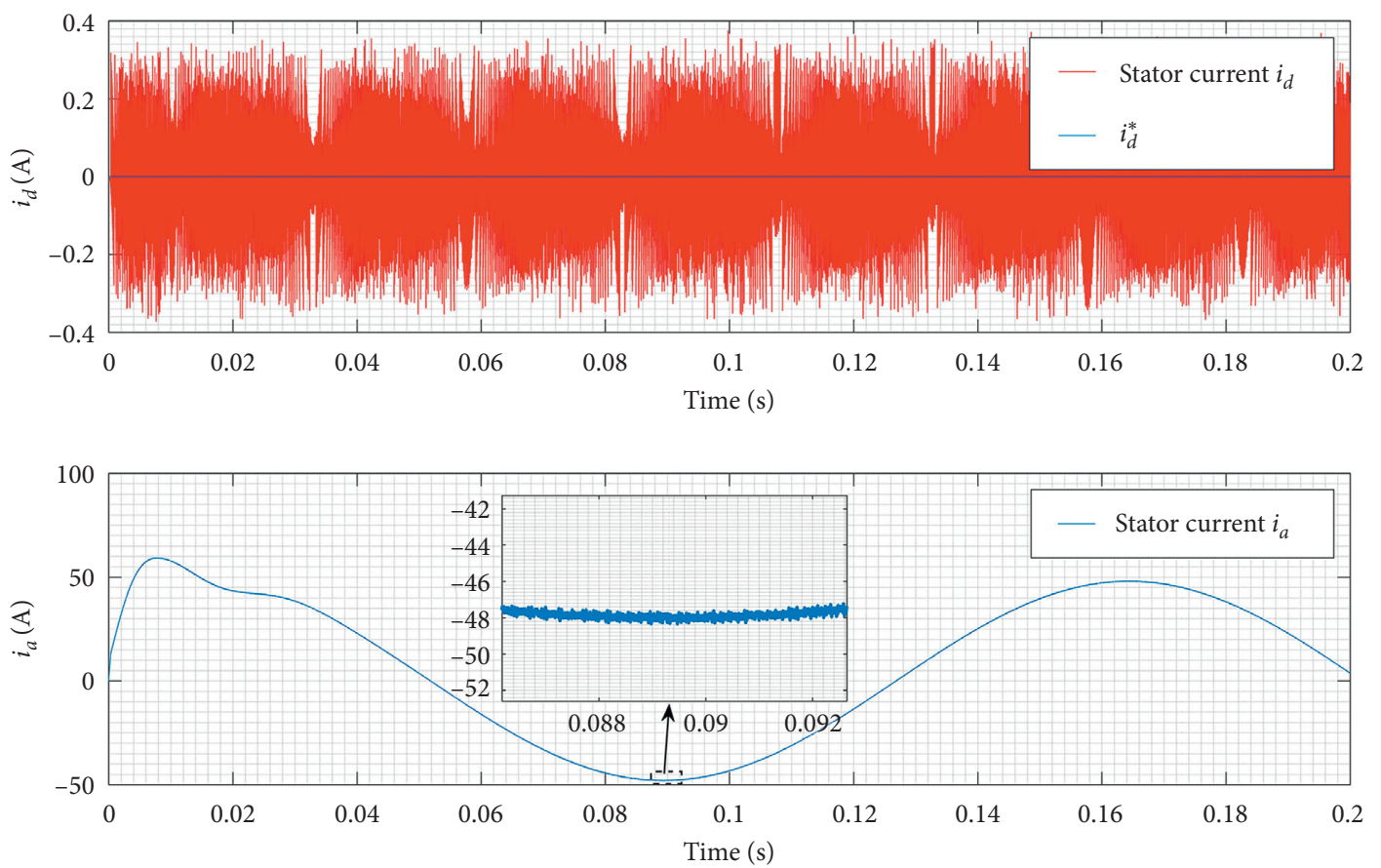

(a)

Figure 5: Continued. 

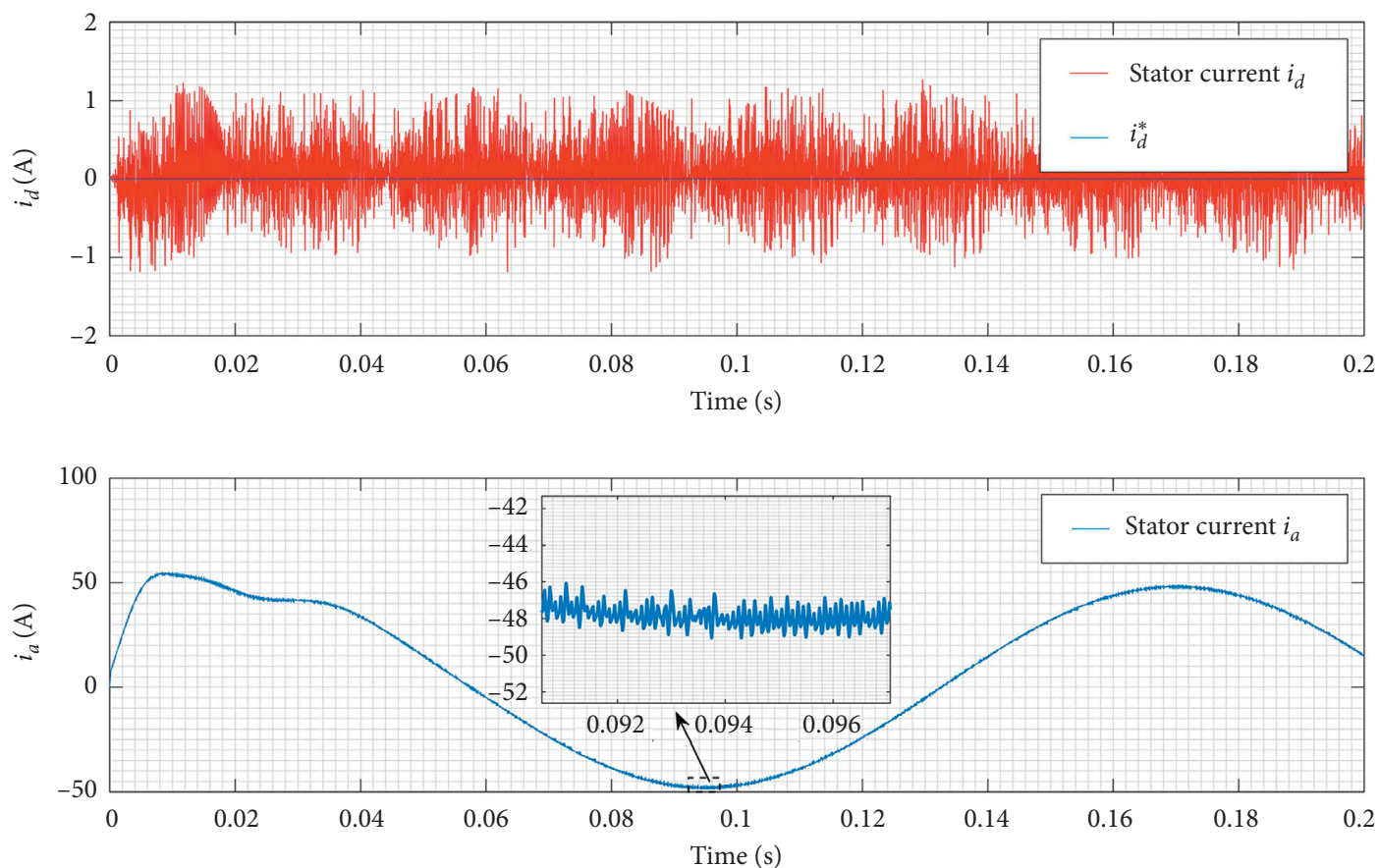

(b)

FIGURE 5: Comparison of $d$-axis current and A-phase current between N3V-MPCC and PI-FOC control strategies. (a) N3V-MPCC. (b) PIFOC.

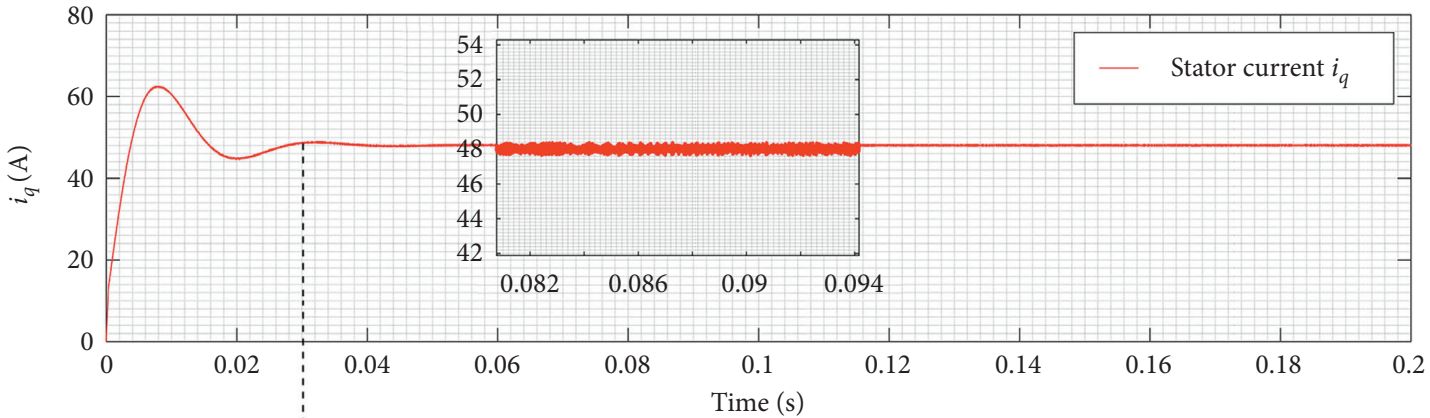

(a)

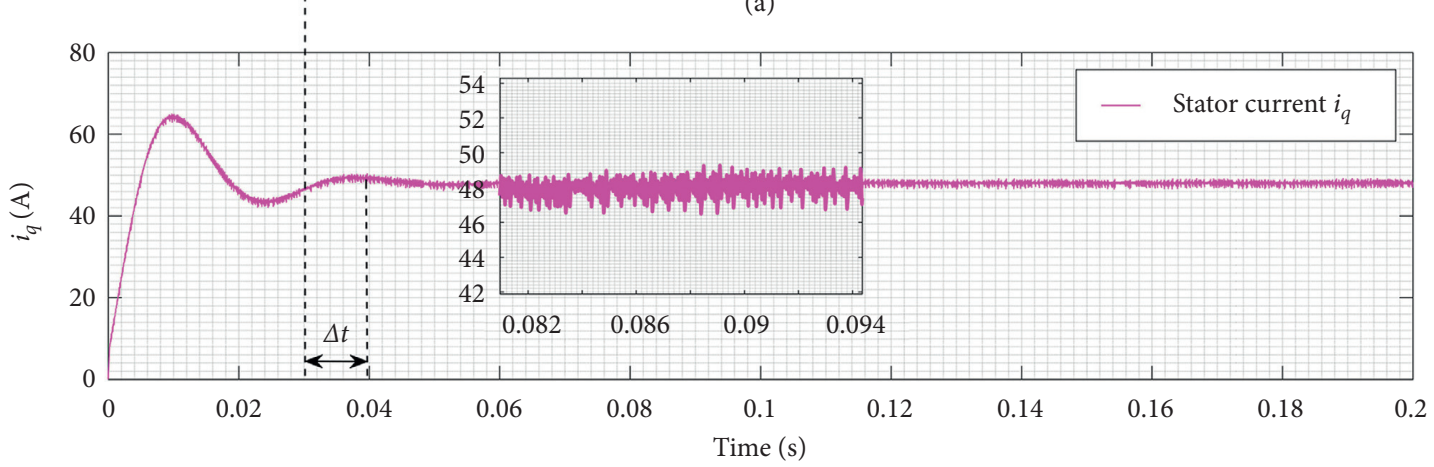

(b)

Figure 6: Comparison of $q$-axis current between N3V-MPCC and PI-FOC control strategies. (a) N3V-MPCC. (b) PI-FOC. 


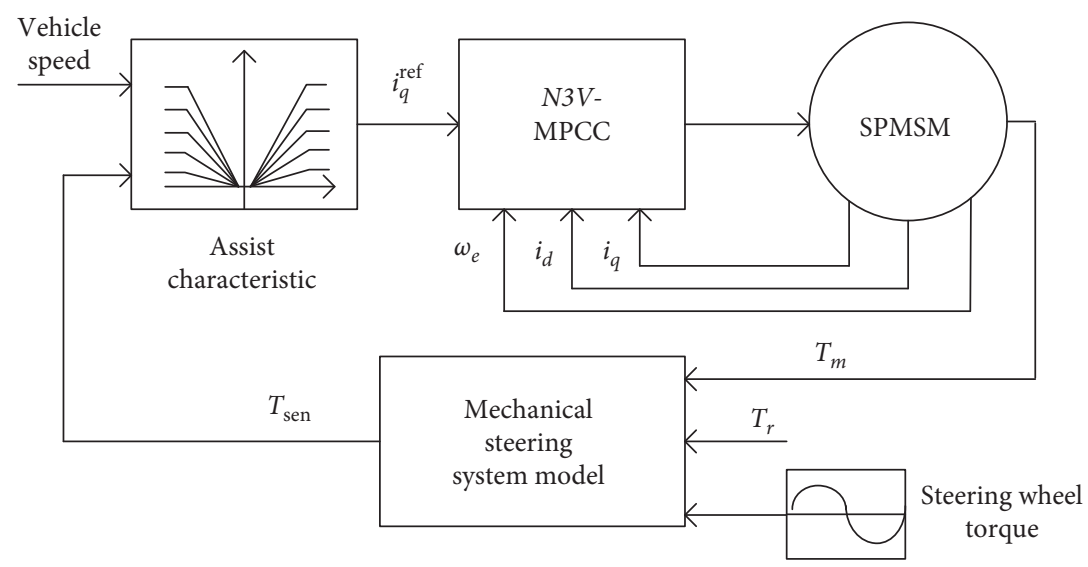

FIGURE 7: EPS system simulation structure diagram.

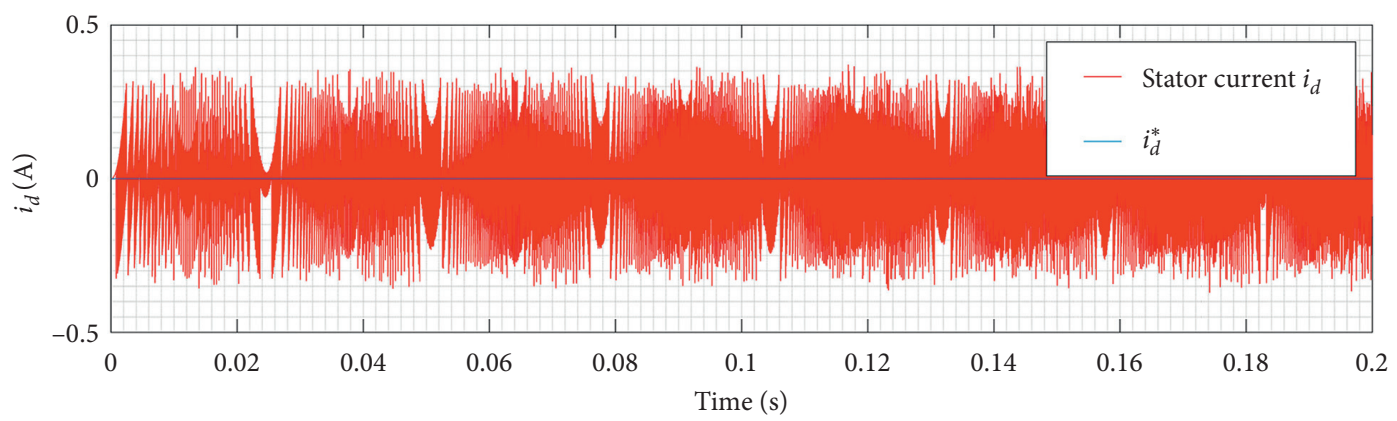

(a)

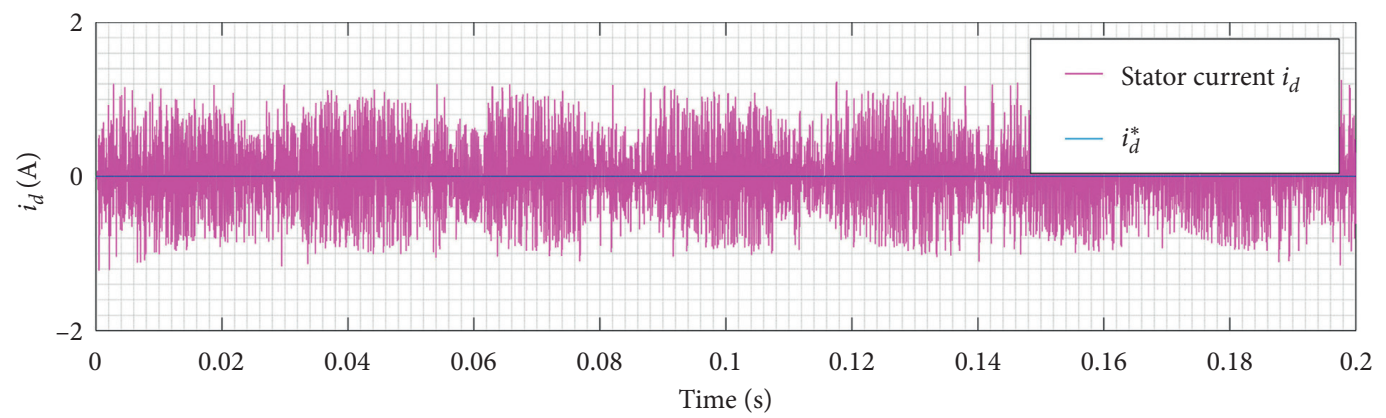

(b)

FIgURE 8: Comparison of $d$-axis current between N3V-MPCC and PI-FOC control strategies when steering resistance increases. (a) N3VMPCC. (b) PI-FOC.

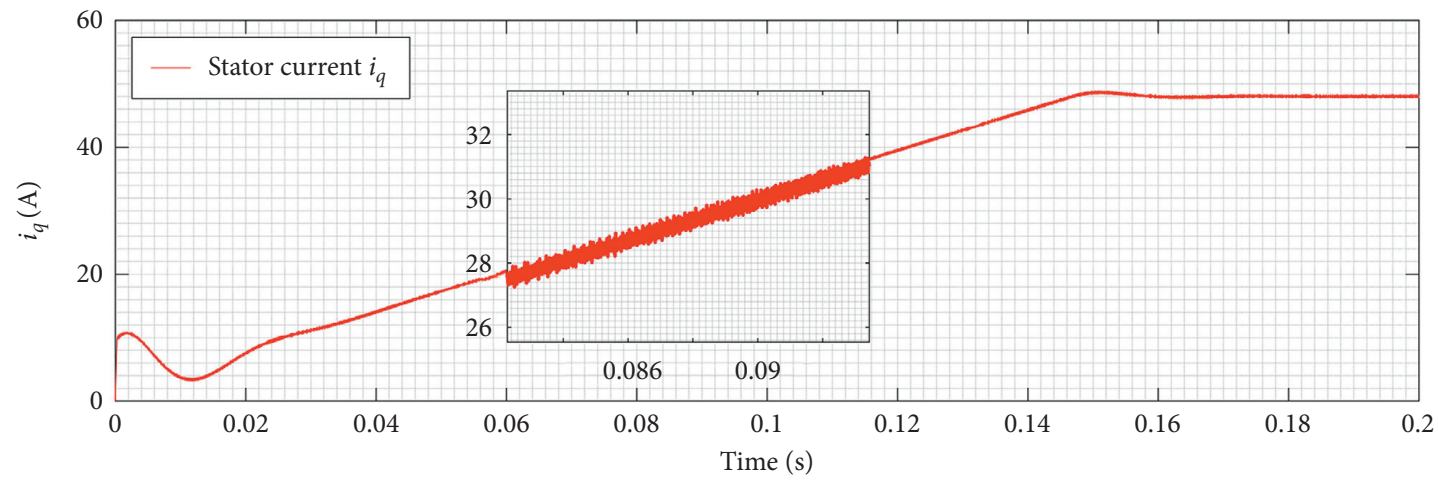

(a)

FIgURE 9: Continued. 


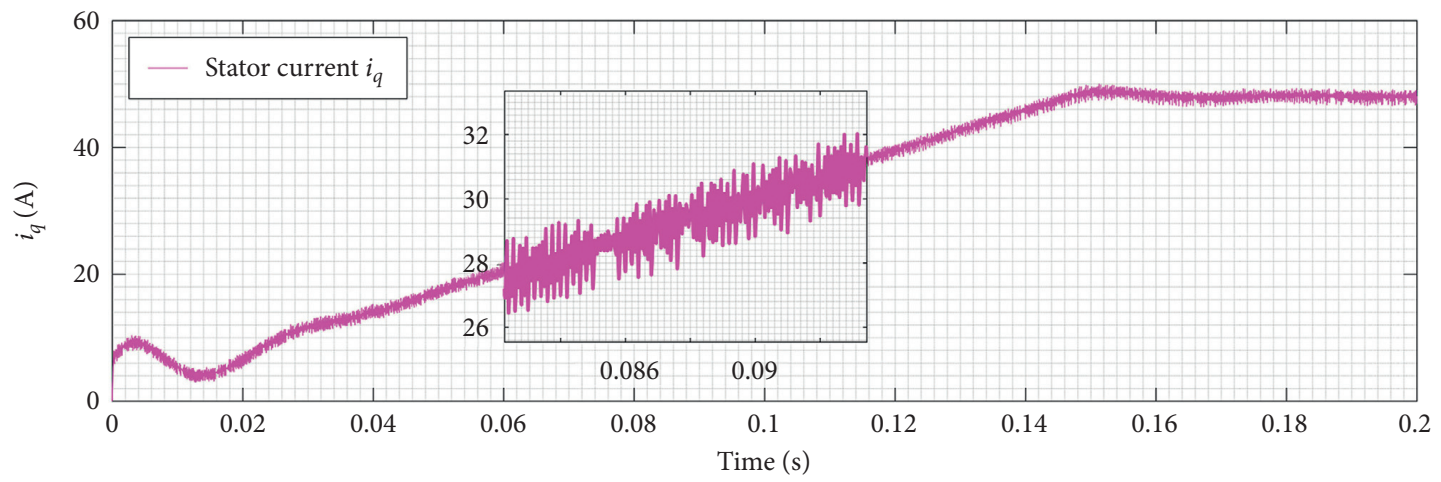

(b)

Figure 9: Comparison of $q$-axis current between N3V-MPCC and PI-FOC control strategies when steering resistance increases. (a) N3VMPCC. (b) PI-FOC.

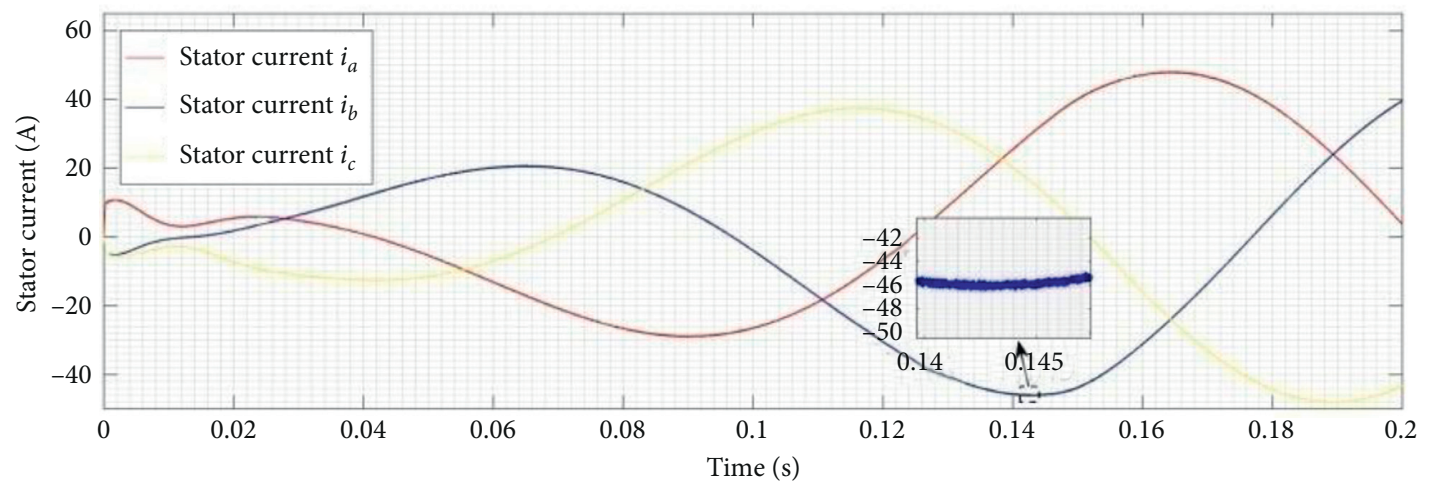

(a)

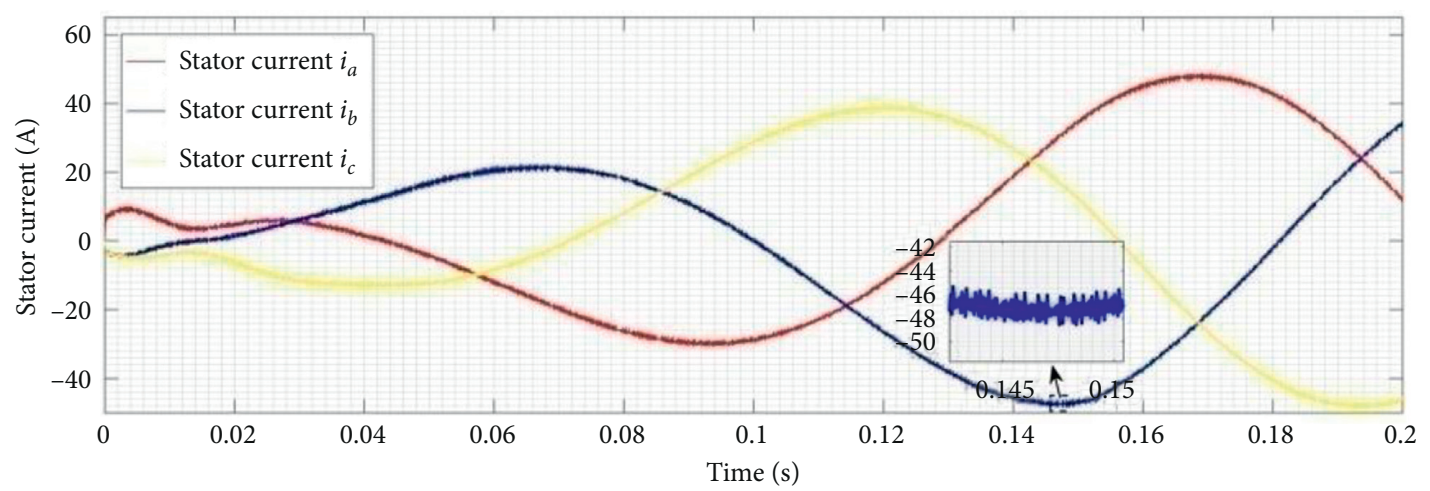

(b)

FIGURE 10: Comparing the three-phase current of N3V-MPCC and PI-FOC control strategies when the steering resistance increases. (a) N3V-MPCC. (b) PI-FOC.

For safety, in the actual vehicle experiment, the steering performance of the motor in a static state is tested. Rotate the steering wheel back and forth to collect the motor current. To facilitate analysis, the collected three-phase current is transformed into $d$-axis and $q$-axis currents through Park's transformation and Clarke's transformation, and then the comparative analysis is performed. Figure 12 shows the SPMSM current of N3V-MPCC and PI-FOC. Under N3V-
MPCC and PI-FOC control strategies, the ripple current decreases with the current decrease and increases with the current increase. N3V-MPCC has better current followability, and the maximum current ripple amplitude is $0.8 \mathrm{~A}$. The maximum current ripple amplitude of the PI-FOC control strategy is $2 \mathrm{~A}$. When turning the steering wheel at a small angle, the ripple current is low, and the steering feel is better; when the steering wheel is rotated at a large angle, the 


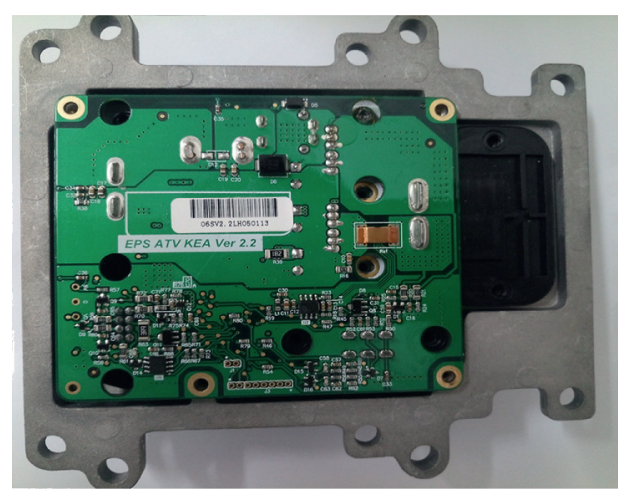

(a)

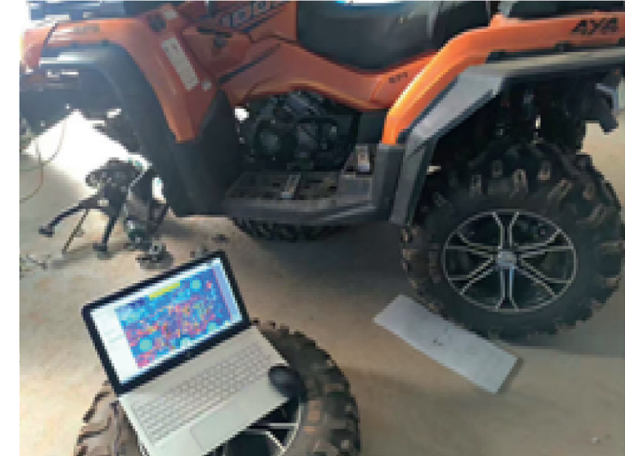

(b)

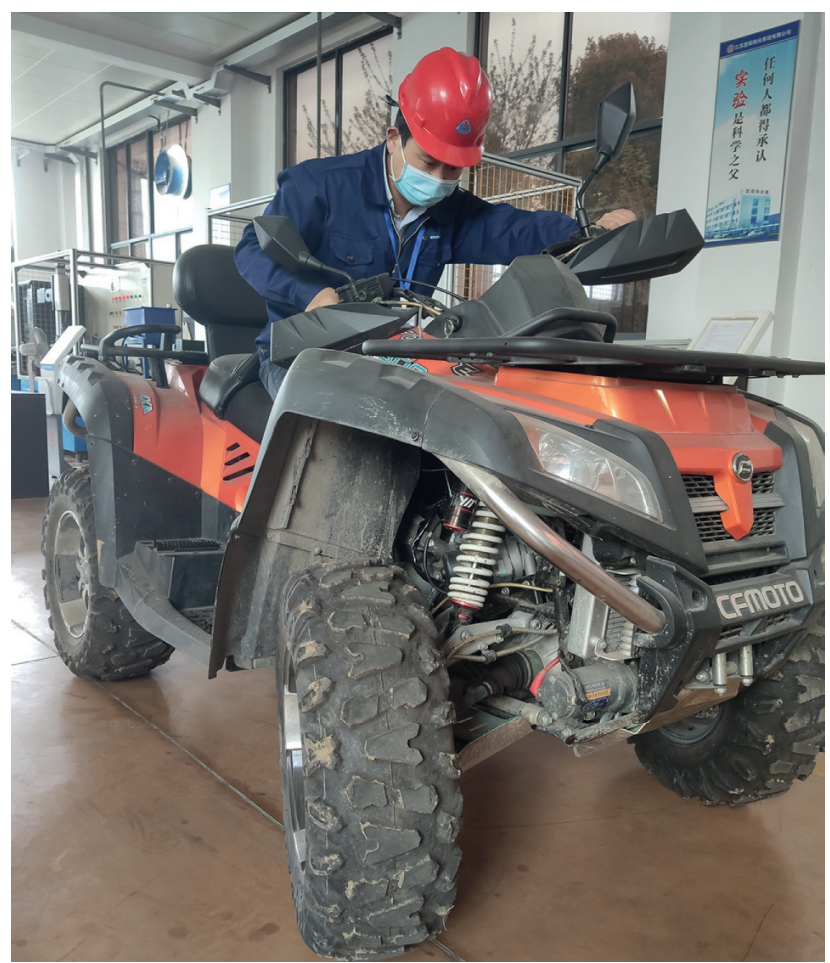

(c)

FIGURE 11: Experiment with vehicle performance of N3V-MPCC and PI-FOC control strategies.

ripple current is higher, and the steering feel is slightly worse. However, the ripple current of N3V-MPCC is generally lower than that of PI-FOC, and the steering feel is better.

To analyze the torque fluctuation during the starting process and to measure the response speed of the system, the experiment condition designed in this paper is: when the vehicle does not start, torque is applied to the handlebar steering wheel. Then, the vehicle ignites, the EPS runs, and the torque fluctuation of the steering wheel is measured. Rotate the handle steering wheel repeatedly at a speed of $0.5 \mathrm{r} / \mathrm{s}$ to measure the torque of the handle steering wheel. The steering torque of the N3V-MPCC control strategy and the PI-FOC control strategy is compared, as shown in Figure 13. Both control methods have large torque fluctuations at the beginning. The system soon stabilized. The bottom line in the figure is the return phase of the steering wheel. At this point, the system has stabilized, so the current ripple disappears. It can be seen from the figure that both N3V-MPCC and PI-FOC control strategies can achieve the function of reducing the steering torque and achieve the purpose of easy steering. The torque pulsation of PI-FOC is $0.8 \mathrm{~N} \cdot \mathrm{m}$, and the torque pulsation of N3VMPCC is $0.3 \mathrm{~N} \cdot \mathrm{m}$. It shows that the steering torque pulsation of N3V-MPCC is smaller, has adequate torque stability, and feels better. 


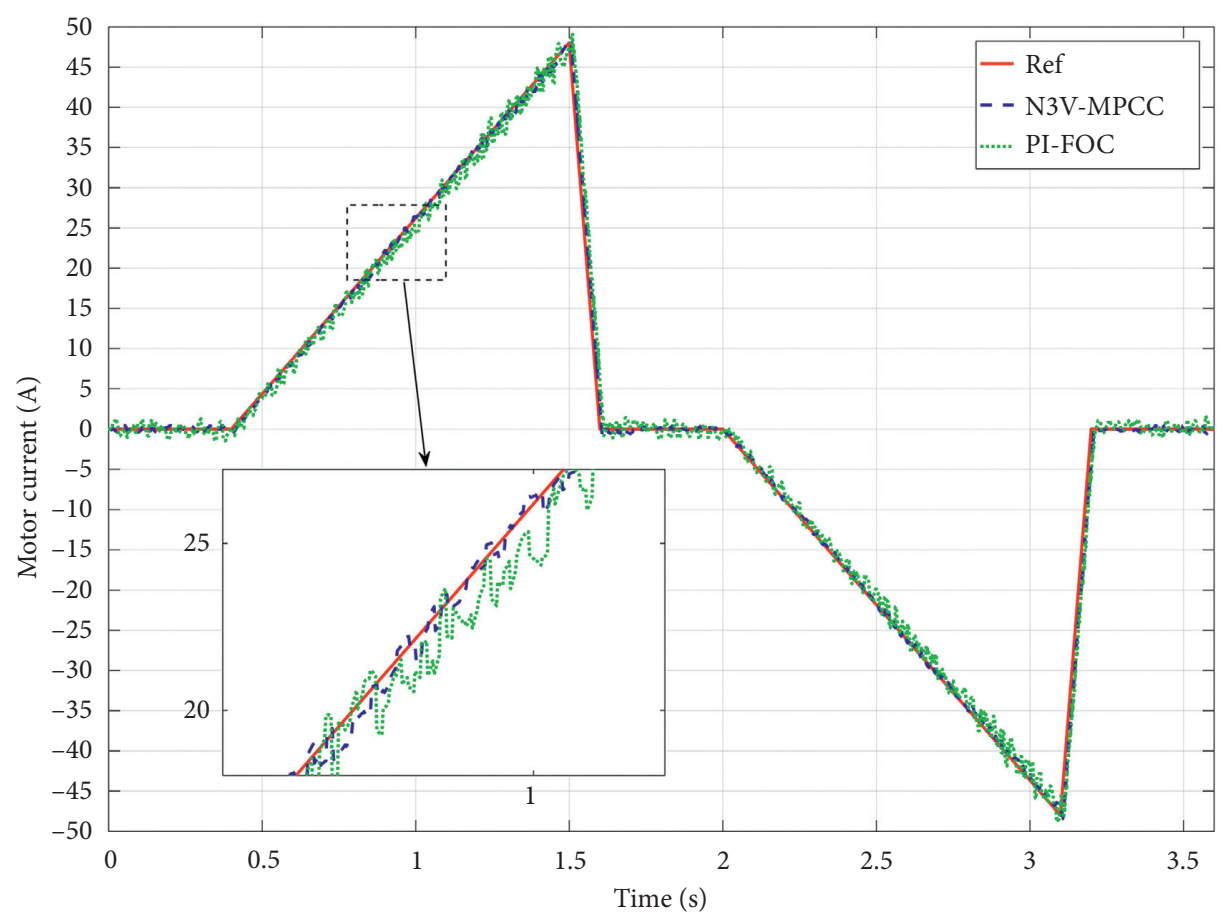

FIGURE 12: SPMSM current.

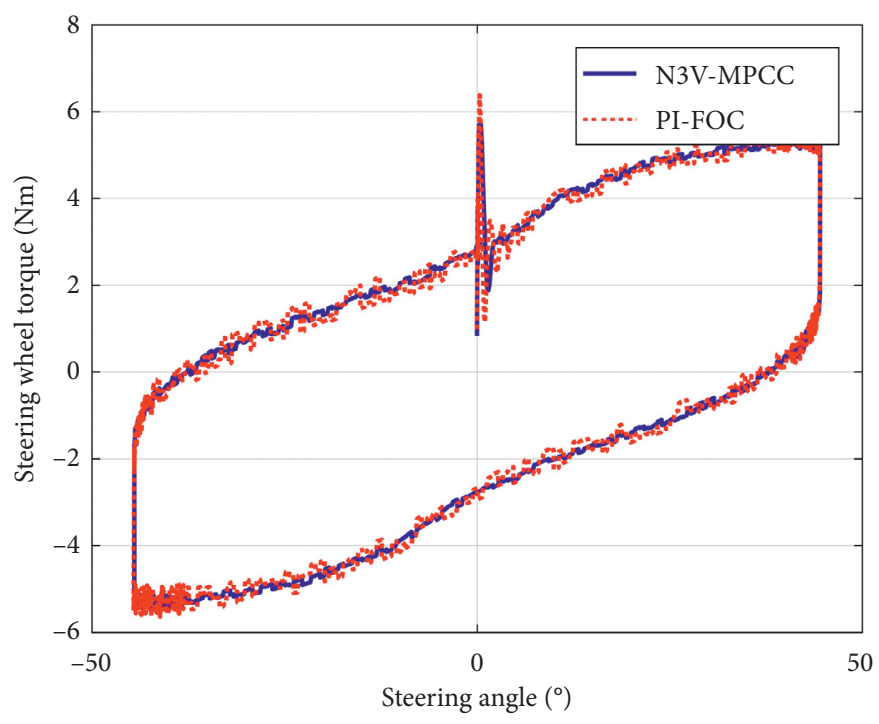

FIgURE 13: Relationship between steering torque and the steering angle.

\section{Conclusions}

The classic PI-FOC control strategy is based on past errors to track the target, and the idea of MPCC is based on the mathematical model of the system to predict future errors and track the target. MPCC does not require complicated PID parameter tuning and has the advantages of simple structure, fast dynamic response, and small steady-state error. This paper applies the MPCC algorithm to the EPS system of ATV. When the SPMSM drive uses a single-vector MPCC, the direction and amplitude of the output voltage vector in the control period are limited and with a higher ripple current. When using a two-vector drive, the calculation load of selecting the second vector is relatively large, and it is difficult to apply to embedded systems. In order to reduce the ripple current and the calculation load, this paper proposes an N3V-MPCC algorithm. In a control cycle, the first optimal voltage vector is found through six predictions. The error voltage vector is calculated based on the target current and the prediction model, and the sector where the error voltage vector is located by the Sector Vector Selection method is determined. In this way, the second effective 
voltage vector is selected. Finally, adjust the amplitude of the output voltage vector through the zero-voltage vector, and calculate the duration of each voltage and output it to VSI. Through the simulation results of MATLAB/Simulink, compared with PI-FOC, N3V-MPCC can effectively reduce the $d$-axis and $q$-axis ripple current, having a better decoupling effect and faster dynamic response. The $q$-axis current ripple of the N3V-MPCC is reduced by $66.67 \%$. Experimental results show that the current ripple of the motor is reduced by $60 \%$. The steady-state performance of N3V-MPCC and PI-FOC algorithms is almost the same. Still, the N3V-MPC control strategy can provide faster response and better dynamic performance with prediction and optimization technology. Through real-vehicle experiments, it is verified that the proposed N3V-MPCC effectively reduces the current ripple of the motor, has a faster dynamic response characteristic, and makes a more stable steering torque and a better steering feel. Since the N3V-MPCC has a strong dependence on the parameters of the prediction model, changes in the parameters will increase the prediction error, resulting in poor control performance. In the working state of the SPMSM, as the temperature increases, the inductance will have a more remarkable change, which will reduce the control accuracy. Therefore, subsequent researches need to be carried out on the automatic identification of inductance parameters.

\section{Data Availability}

The data used to support the findings of this study are available from the corresponding author upon request.

\section{Conflicts of Interest}

The authors declare that they have no conflicts of interest regarding the publication of this paper.

\section{References}

[1] A. M. Azman, T. Noreffendy, and R. F. Redza, "Design and development of low cost all terrain vehicle (ATV)," Applied Mechanics and Materials, vol. 663, no. 3941, pp. 517-521, 2014.

[2] R. D. Ripley, E. P. Nault, and S. D. Taylor, "Power steering for an all terrain vehicle," 2012.

[3] H. J. Park, M. S. Lim, and C. S. Lee, "Magnet shape design and verification for SPMSM of EPS system using cycloid curve," IEEE Access, vol. 35, pp. 37207-137216, 2019.

[4] R. Dutta and M. F. Rahman, "Design and analysis of an interior permanent magnet (IPM) machine with very wide constant power operation range," IEEE Transactions on Energy Conversion, vol. 23, no. 1, pp. 25-33, 2008.

[5] F. Daniel, "Hybrid differential evolution algorithm employed for the optimum design of a high-speed PMSM used for EV propulsion," IEEE Transactions on Industrial Electronics, vol. 64, no. 12, pp. 9824-9833, 2017.

[6] X. Liu, H. Chen, J. Zhao, and A. Belahcen, "Research on the performances and parameters of interior PMSM used for electric vehicles," IEEE Transactions on Industrial Electronics, vol. 63, no. 6, pp. 3533-3545, 2016.
[7] S. Na, Z. Li, F. Qiu, and C. Zhang, "Torque control of electric power steering systems based on improved active disturbance rejection control," Mathematical Problems in Engineering, vol. 2020, no. 6, pp. 1-13, 2020

[8] J. M. Kim, M. H. Yoon, and J. P. Hong, "Analysis of cogging torque caused by manufacturing tolerances of SPMSM for electric power steering," IET Electric Power Applications, vol. 10, no. 8, pp. 697-696, 2016.

[9] A. V. Sant and K. R. Rajagopal, "PM synchronous motor speed control using hybrid fuzzy-PI with Novel switching functions," IEEE Transactions on Magnetics, vol. 45, no. 10, pp. 4672-4675, 2009.

[10] N. V. Quynh, “The fuzzy PI controller for PMSM's speed to track the standard model," Mathematical Problems in Engineering, vol. 2020, pp. 1-20, Article ID 1698213, 2020.

[11] Y. Deng, J. Wang, H. Li, J. Liu, and D. Tian, “Adaptive sliding mode current control with sliding mode disturbance observer for PMSM drives," ISA Transactions, vol. 88, pp. 113-126, 2019.

[12] B. Liu, W. Song, J. Ma, X. Feng, and W. Li, "Dynamic performance improvement of single-phase PWM converters with power hysteresis control scheme," IET Power Electronics, vol. 11, no. 12, pp. 1894-1902, 2018.

[13] X. Zhang, L. Sun, K. Zhao, and L. Sun, "Nonlinear speed control for PMSM system using sliding-mode control and disturbance compensation techniques," IEEE Transactions on Power Electronics, vol. 28, no. 3, pp. 1358-1365, 2013.

[14] M. Preindl, E. Schaltz, and P. Thogersen, "Switching frequency reduction using model predictive direct current control for high-power voltage source inverters," IEEE Transactions on Industrial Electronics, vol. 58, no. 7, pp. 2826-2835, 2011.

[15] P. Cortes, M. P. Kazmierkowski, R. M. Kennel, D. E. Quevedo, and J. Rodriguez, "Predictive control in power electronics and drives," IEEE Transactions On Industrial Electronics, vol. 55, no. 12, pp. 4312-4324, 2008.

[16] S. Kouro, M. A. Perez, J. Rodriguez, A. M. Llor, and H. A. Young, "Model predictive control: MPC's role in the evolution of power electronics," IEEE Industrial Electronics Magazine, vol. 9, no. 4, pp. 8-21, 2015.

[17] K. Koiwa, T. Kuribayashi, T. Zanma, K. Z. Liu, and M. Wakaiki, "Optimal current control for PMSM considering inverter output voltage limit: model predictive control and pulse-width modulation," IET Electric Power Applications, vol. 13, no. 12, pp. 2044-2051, 2019.

[18] X. Zhang, B. Hou, and Y. Mei, "Deadbeat predictive current control of permanent-magnet synchronous motors with stator current and disturbance observer," IEEE Transactions on Power Electronics, vol. 32, no. 5, pp. 3818-3834, 2017.

[19] C. G. Xia, T. Liu, and T. Shi, "A simplified finite-control-set model-predictive control for power converters," IEEE Transactions on Industrial Informatics, vol. 10, no. 2, pp. 991-1002, 2014.

[20] R. Errouissi, A. Al-Durra, S. M. Muyeen, and S. Leng, "Continuous-time model predictive control of a permanent magnet synchronous motor drive with disturbance decoupling," IET Electric Power Applications, vol. 11, no. 5, pp. 697-706, 2017.

[21] Y. Zhang and H. Yang, "Model predictive torque control of induction motor drives with optimal duty cycle control," IEEE Transactions on Power Electronics, vol. 29, no. 12, pp. 65936603, 2014.

[22] M. H. Vafaie, B. Mirzaeian Dehkordi, P. Moallem, and A. Kiyoumarsi, "A new predictive direct torque control 
method for improving both steady-state and transient-state operations of the PMSM," IEEE Transactions on Power Electronics, vol. 31, no. 5, pp. 3738-3753, 2016.

[23] T. Zanma, M. Kawasaki, K. Liu, M. Hagino, and A. Imura, "Model predictive direct torque control for PMSM with discrete voltage vectors," IEEJ Journal of Industry Applications, vol. 3, no. 2, pp. 121-130, 2014

[24] S. Fan and C. Tong, "Model predictive current control method for PMSM drives based on an improved prediction model," Journal of Power Electronics, vol. 20, no. 6, pp. 1456-1466, 2020.

[25] X. Zhang, L. Zhang, and Y. Zhang, "Model predictive current control for PMSM drives with parameter robustness improvement," IEEE Transactions on Power Electronics, vol. 34, no. 2, pp. 1645-1657, 2019.

[26] W. Wang, M. Cheng, and B. F. Zhang, "A fault-tolerant permanent-magnet traction module for subway applications," IEEE Transactions on Power Electronics, vol. 29, no. 4, pp. 1646-1658, 2013.

[27] Y. C. Zhang, J. L. Liu, G. F. Yuan, and Z. X. Li, “An improved model predictive control with duty cycle control for PMSM drives," 2017.

[28] Y. Zhang, D. Xu, J. Liu, S. Gao, and W. Xu, "Performance improvement of model-predictive current control of permanent magnet synchronous motor drives," IEEE Transactions on Industry Applications, vol. 53, no. 4, pp. 3683-3695, 2017.

[29] Y. Zhang, Y. Peng, and H. Yang, "Performance improvement of two-vectors-based model predictive control of PWM rectifier," IEEE Transactions on Power Electronics, vol. 31, no. 8, pp. 6016-6030, 2016.

[30] Y. Zhang and H. Yang, "Generalized two-vector-based modelpredictive torque control of induction motor drives," IEEE Transactions on Power Electronics, vol. 30, no. 7, pp. 38183829, 2015.

[31] X. H. Wang and D. Sun, “Three-vector-based low-complexity model predictive direct power control strategy for doubly fed induction generators," IEEE Transactions on Power Electronics, vol. 32, no. 1, pp. 773-782, 2016.

[32] Y. Yan, S. Wang, C. Xia, H. Wang, and T. Shi, "Hybrid control set-model predictive control for field-oriented control of VSIPMSM," IEEE Transactions on Energy Conversion, vol. 31, no. 4, pp. 1622-1633, 2016.

[33] Z. C. Liu and Y. Zhao, "Robust perturbation observer-based finite control set model predictive current control for SPMSM considering parameter mismatch," Energies, vol. 12, no. 19, p. 3711, 2019.

[34] Y. Lee and J.-I. Ha, "Control method for mono inverter dual parallel surface-mounted permanent-magnet synchronous machine drive system," IEEE Transactions on Industrial Electronics, vol. 62, no. 10, pp. 6096-6107, 2015. 